\title{
A PERCEPÇÃO DA MONITORIA COMO ELEMENTO DE FORTALECIMENTO DO ENSINO-APRENDIZAGEM NA ÁREA DE ENGENHARIA DE TRANSPORTES
}

\author{
THE PERCEPTION OF ACADEMIC MONITORING AS AN ELEMENT OF STRENGTHENING \\ TEACHING-LEARNING IN THE AREA OF TRANSPORTATION ENGINEERING \\ Bruno Cavalcante Mota ${ }^{1}$, Francisco Heber Lacerda de Oliveira ${ }^{2}$ \\ DOI: 10.37702/REE2236-0158.v40p373-382.2021
}

\begin{abstract}
RESUMO
Durante a educação superior, a troca de saberes e experiências é evidenciada a partir do desenvolvimento de estratégias dialógicas para a construção de conhecimentos entre pares, permitindo que discentes e docentes se sintam responsáveis pelo processo de ensino-aprendizagem. No contexto dessa formação, a monitoria acadêmica ganha relevância. Nesse âmbito, durante as disciplinas ofertadas pelo Departamento de Engenharia de Transportes da Universidade Federal do Ceará (UFC), é desenvolvida uma série de atividades com os discentes por meio do Programa de Iniciação à Docência. Dessa forma, o objetivo deste trabalho é avaliar a percepção dos discentes monitorados no curso de Engenharia Civil em relação às atividades de monitoria, por meio de um questionário no qual os alunos permeiam entre a discordância total e a concordância total em oito afirmativas sobre o processo em questão. Os resultados mostraram que a maioria dos alunos consideraram a monitoria como meio de fortalecimento do ensino e que ela exerceu impacto positivo no decorrer da disciplina.
\end{abstract}

Palavras-chave: docência; monitoria; aprendizagem; Engenharia Civil.

\begin{abstract}
During higher education, the exchange of knowledge and experiences is evidenced by the development of dialogic strategies for the construction of knowledge among peers, allowing students and teachers to feel responsible for the teaching-learning process. In the context of this training, academic monitoring gains relevance. In this context, during the disciplines offered by the Department of Transportation Engineering of the Federal University of Ceará (UFC), a series of activities are developed with students through the Teaching Initiation Program. Thus, the objective of this paper is to evaluate the perception of the students monitored in the course of Civil Engineering in relation to the monitoring activities, in which, by means of a questionnaire, the students interspersed between total disagreement and total agreement in eight affirmations about the process in question. The results showed that most students considered monitoring as a means of strengthening teaching and that it had a positive impact on the course.
\end{abstract}

Keywords: teaching; monitoring; learning; Civil Engineering.

\footnotetext{
${ }^{1}$ Mestrando em Engenharia de Transportes da Universidade Federal do Ceará; brunomota@ det.ufc.br

${ }^{2}$ Professor Adjunto da Universidade Federal do Ceará; heber@ det.ufc.br
} 


\section{INTRODUÇÃO}

O ensino superior tem sido muito modificado e, por meio dos avanços sociais, éticos, econômicos e políticos, passa a exigir um novo olhar para formar profissionais, possibilitando a quebra de paradigmas na formação atual, com foco nas necessidades do discente (MESQUITA; MENESES; RAMOS, 2016). Nesse contexto, a monitoria surge como um elemento de suporte ao desenvolvimento do processo de ensino-aprendizagem. Conforme Lins (2007), a monitoria na formação superior consiste em uma atividade acadêmica de natureza complementar, que permite ao aluno desenvolver e ampliar os conhecimentos adquiridos em sala de aula.

$\mathrm{Na}$ Universidade Federal do Ceará (UFC), a monitoria é regida pela Resolução $\mathrm{n}^{\circ} 08$ do Conselho de Ensino, Pesquisa e Extensão (CEPE), que se constitui em uma ação didáticopedagógica institucional desenvolvida no âmbito dos diversos cursos de graduação (UFC, 2013). De acordo com a Pró-Reitoria de Graduação da UFC, no ano de 2020 foram selecionados 730 bolsistas remunerados para fornecerem suporte a mais de 15.000 alunos de graduação (PROGRAD, 2020).

A Resolução (UFC, 2013) foi elaborada na forma do que dispõe o artigo 84 (BRASIL, 1996) do estatuto em vigor em âmbito nacional, deliberando que:

os discentes da educação superior poderão ser aproveitados em tarefas de ensino e pesquisa pelas respectivas instituições, exercendo funções de monitoria, de acordo com seu rendimento e seu plano de estudos. (BRASIL, 1996)

Para Melo (2013), os programas de monitoria são elaborados com base em um conjunto de estratégias que objetivam o complemento da formação dos discentes por meio de atividades auxiliares de ensino, nas quais um outro estudante, intitulado monitor, que já tenha cursado a disciplina, possuindo uma carga maior de conhecimentos, compartilha suas experiências e saberes com os demais, sob supervisão de um professororientador.
Intitulado, na UFC, Programa de Iniciação à Docência (PID), a monitoria tem como objetivo a contribuição para o processo de formação do aluno de graduação, proporcionando a participação do estudantemonitor nas atividades docentes, facilitando a interação entre estudantes e professores nas atividades de ensino, visando à melhoria da aprendizagem.

Dessa forma, este artigo tem o objetivo de abordar a percepção dos alunos do curso de Engenharia Civil, que foram assistidos pelas monitorias das disciplinas ofertadas pelo Departamento de Engenharia de Transportes (DET), frente à importância do PID no processo de ensino-aprendizagem e à contribuição do programa para a sua formação acadêmica. Essa percepção será utilizada para analisar se a monitoria pode ser entendida como um elemento de fortalecimento do processo em questão, contribuindo para a troca de saberes e experiência, além de colaborar para o êxito acadêmico nas disciplinas.

\section{FUNDAMENTAÇÃO TEÓRICA}

O ensino-aprendizagem acontece por meio de processos de educação, sejam eles formais, não formais e informais, de acordo com o contexto no qual o aluno esteja inserido. Dentro dessa conjuntura, a educação não formal, segundo Aguiar et al. (2016), estabelece-se como uma atividade aberta, que pode ser moldada conforme a área e o objeto de estudo. Menestrina e Bazzo (2008) citam atividades como a monitoria, os projetos multidisciplinares e iniciação científica como ações de incentivo a uma mudança de conceito de sala de aula, que permite não restringir a aprendizagem a quatro paredes.

Amorim, Paixão e Silva (2017) consideraram relevante a monitoria como atividade complementar do processo de ensinoaprendizagem dos estudantes da disciplina de Química Geral e Inorgânica I, devido à possibilidade dos diversos papeis de o monitor contribuir para o esclarecimento do conteúdo e para a melhoria do aprendizado. Os autores ainda relataram que o auxílio do monitor nas diversas atividades realizadas na disciplina 
contribuiu para o desenvolvimento do raciocínio crítico, no que diz respeito ao conteúdo e, consequentemente, para um melhor rendimento do aluno.

Para Ferraz et al. (2009), a monitoria se torna uma ferramenta de apoio pedagógico com o objetivo de possibilitar o desenvolvimento de habilidades técnicas, além de fornecer um aprofundamento teórico, proporcionando o aperfeiçoamento acadêmico do estudante. Nesse contexto, para Pinheiro et al. (2019), a partir do elo entre a importância da monitoria e o processo de ensino-aprendizagem, chega-se aos processos de adquirir, transmitir e compreender o conhecimento, evadindo-se da redoma conteúdo-nota-aprovação.

Frison e Moraes (2010) sintetizam que:

[...] compreende-se por monitoria uma estratégia de apoio ao ensino em que estudantes mais adiantados nos programas de formação acadêmica colaboram nos processos de apropriação do conhecimento de seus colegas. (FRISON; MORAES. 2010, p. 145)

De acordo com Jesus et al. (2012), os alunos assistidos pelo programa de monitoria aprendem de forma mais interativa e dinâmica, desenvolvendo o controle de seu próprio processo de aprendizagem, a partir da autorregulação da aprendizagem. Além disso, os alunos encontram um ambiente motivador para a sua aprendizagem, devido ao ensino se decorrer entre pares, haja vista o fato de que o monitor e o monitorado, na maioria das vezes, compartilham da mesma forma de pensar e de se comunicar.

Para Araújo e Moreira (2005), o monitor torna-se importante para o sucesso de um curso, em virtude da personalização do ensino causada mediante ao apoio organizado e sistemático, fornecendo estímulos e orientação ao aluno que apresenta dificuldades de aprendizado, facilitando-lhe os processos de aprendizagem. De acordo com Santos, Boscaino e Pavão (2006), essa ligação entre alunos monitorados e aluno-monitor "permite que o primeiro se sinta mais confortável nessa etapa do ensino superior" (SANTOS; BOSCAINO; PAVÃO, 2006, p. 8).

Existe uma sensação de conforto relativa à disciplina quando o aluno convive diretamente com o monitor, pois esse último é visto, pelos demais, como aluno que já vivenciou as experiências daquela disciplina e está disponível, naquele momento, para trocar informações valiosas para a melhoria do aprendizado (SILVEIRA; SALES, 2016).

Sousa Júnior et al. (2009) afirmam que a aproximação entre os alunos monitorados, os professores orientadores e os alunos monitores possibilitam a disseminação do conhecimento adquirido por todos os atores do processo. Além disso, a monitoria é ponto de acesso para uma carreira docente, propiciando ao aluno monitor a melhoria do seu aprendizado, permitindo que fique mais próximo de desempenhar um papel acadêmico na instituição. Essa observação está em sintonia com o abordado por Andrade et al., os quais, por meio de entrevistas realizadas com alunos, monitores e professores, concluíram que "a monitoria se apresenta como propulsora dos êxitos nos processos de formação" (ANDRADE et al., 2018, p. 1695).

Araújo et al. (2019) avaliaram a contribuição da monitoria, nas Bases Teóricas e Técnicas do curso de Enfermagem, diante da percepção de graduandos. Por efeito das entrevistas realizadas com os alunos, foram identificados núcleos de resposta que convergiam para o entendimento da monitoria como fortalecimento do processo de aprendizagem. $\mathrm{O}$ enriquecimento do conhecimento visto em sala de aula, durante a monitoria, foi evidenciado pela maioria dos entrevistados.

\section{MÉTODO DE PESQUISA}

Com a coleta de informações e constatações obtidas a partir da revisão da literatura, elaborou-se um questionário de percepção, no qual os alunos assistidos avaliaram afirmações sobre o programa de monitoria, em diferentes graus de concordância. Utilizou-se a Escala Likert devido às propriedades básicas oferecidas, 
como confiabilidade, validade e sensibilidade aos resultados. Backer (1995) explica que a Escala Likert requer que os entrevistados indiquem seu grau de concordância ou discordância com afirmações relativas a um determinado assunto. Mattar (2001) explica que a cada item de resposta é atribuído um número, capaz de refletir a tendência da atitude dos respondentes em relação às afirmações realizadas. Desse modo, os estudantes utilizaram a seguinte classificação: (1) para discordo totalmente, (2) para discordo parcialmente, (3) para neutro, (4) para concordo parcialmente e (5) para concordo totalmente.

$\mathrm{O}$ questionário foi elaborado na plataforma Google Forms, enviado para os estudantes pelo Sistema Integrado de Gestão de Atividades Acadêmicas da UFC, o SIGAA, por meio do qual os alunos identificavam apenas o seu semestre atual na graduação, a disciplina mais recente na qual tinha sido assistido pela monitoria e o caráter dela: teórica, prática ou teórico-prática. $\mathrm{Na}$ sequência, havia oito afirmativas para os alunos analisarem, a saber:

1) a monitoria na disciplina propiciou troca de saberes e experiência;

2) a monitoria é um processo de aprendizagem formal;

3) a monitoria é agente facilitador de um processo efetivo de ensinoaprendizagem;

4) existe o sentimento de igualdade entre o monitor e o discente acompanhado;

5) a monitoria fortaleceu o conteúdo repassado em sala de aula;

6) o monitor pôde ser visto como um elemento de interlocução e mediação entre a turma e o professor;

7) o discente acompanhado se sentiu mais confiante para a realização das provas após as aulas de monitoria;

8) as atividades realizadas pelo monitor contribuíram para o êxito ao final da disciplina.

O público-alvo do questionário foi os alunos das disciplinas de Topografia, Projeto e Construção da Infraestrutura Viária (PCIV) e
Projeto e Construção da Superestrutura Viária (PCSV), ofertadas ao curso de Engenharia Civil da Universidade Federal do Ceará, no terceiro, sexto e sétimo semestre, respectivamente. $\mathrm{O}$ questionário ficou ativo durante 15 dias. As disciplinas mencionadas abrangeram, respectivamente, 120 alunos, 90 alunos e 60 alunos durante o ano letivo de 2019. O questionário permitiu a identificação de 82 unidades de registro, sendo 8 alunos de Topografia, 22 alunos de PCIV, 52 alunos de PCSV. Após o procedimento de análise, foram realizadas correlações entre os resultados obtidos e os estudos realizados com o tema, para os quais foi possível contrapor ou confirmar a afirmação.

\section{RESULTADOS E DISCUSSÕES}

Do público-alvo, um percentual de $30,4 \%$ participou do questionário. A maioria são alunos da disciplina de PCSV. Apesar de a disciplina de Topografia deter o maior número de alunos, foi a que obteve menos registros de resposta, fato que pode ser explicado pela baixa adesão ao questionário entre os alunos que a cursaram em 2019. Entre as avaliadas, é a única disciplina considerada de caráter teóricoprático, pois as demais são de caráter apenas teórico. Os Gráficos 1 e 2 apresentam a identificação dos alunos.

\section{Gráfico 1-Semestre dos alunos respondentes}

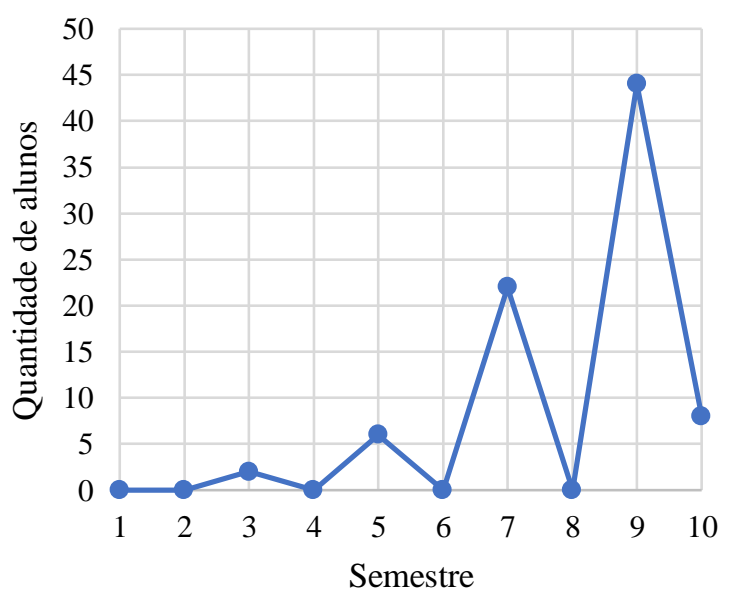

Fonte: elaborado pelos autores (2020). 
Gráfico 2 - Alunos por disciplinas da monitoria

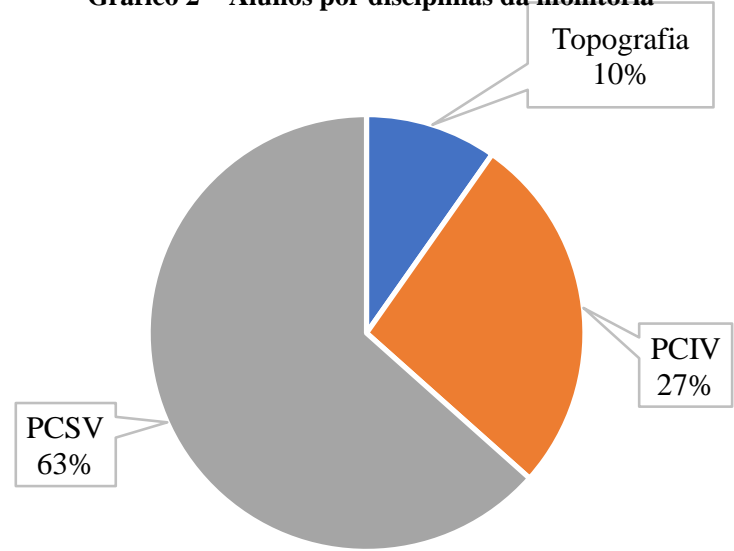

- Topografia - PCIV $\approx \mathrm{PCSV}$

Percebe-se que os semestres de quem respondeu ao questionário são, em sua maioria, o $5^{\circ}$, o $7^{\circ}$ e o $9^{\circ}$, que correspondem ao semestre subsequente às disciplinas de Topografia, PCIV e PCSV, respectivamente. Como observado no Gráfico 2, mais de $60 \%$ dos registros de respostas são provenientes de alunos da disciplina de PCSV, seguidos dos da disciplina de PCIV e Topografia. O Gráfico 3 apresenta os resultados do questionário de percepção aplicado.

Fonte: elaborado pelos autores (2020).

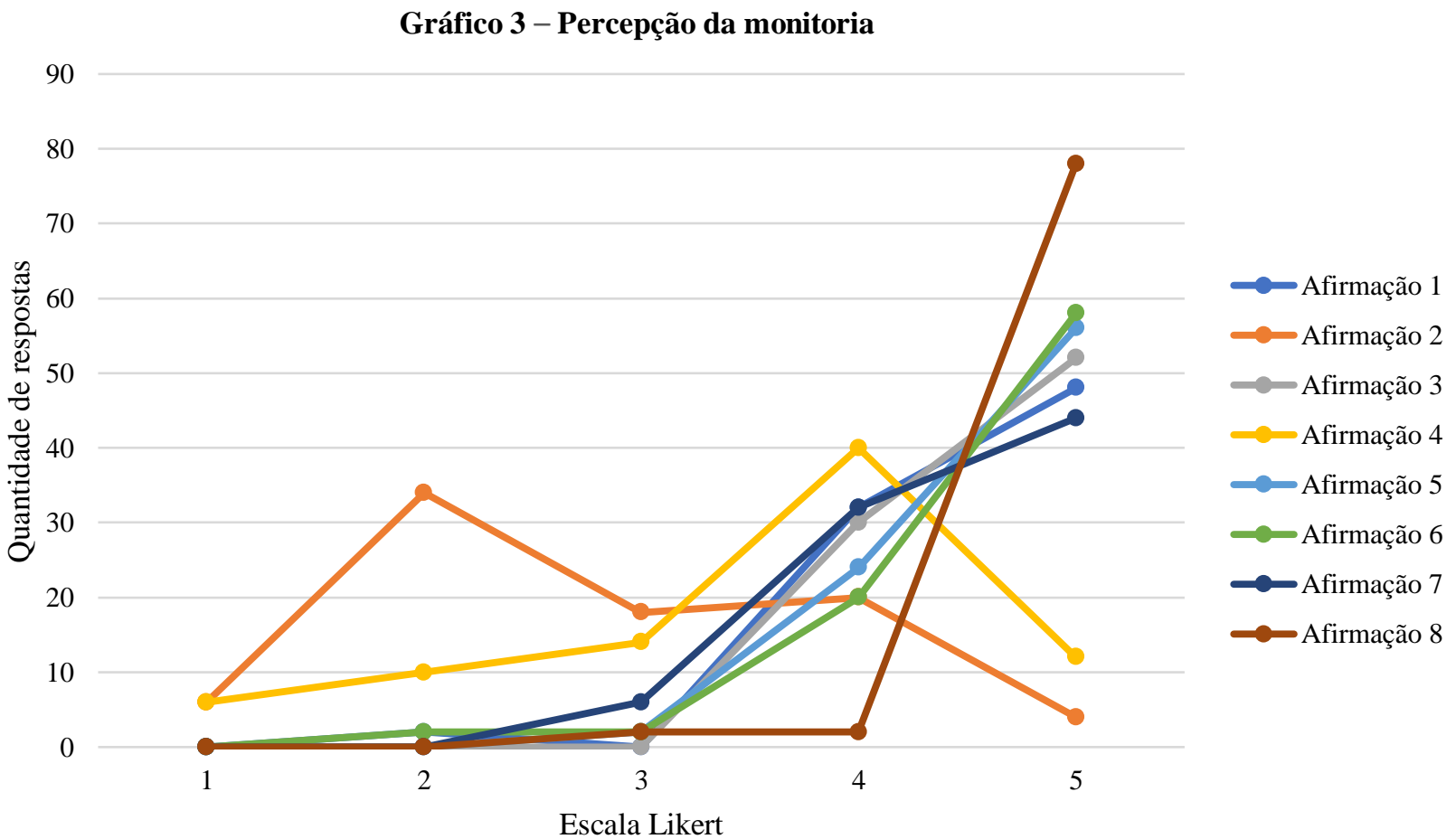

Fonte: elaborado pelos autores (2020).

Com relação às afirmativas, percebe-se que a Afirmação (8) detém o maior número de avaliação 5 da Escala Likert, chegando a representar $95 \%$ do total de respostas, o que comprova que as ações desenvolvidas pelo monitor contribuíram para o êxito final na disciplina, de acordo com a percepção dos alunos. Essa elevada concordância total é sustentada por Andrade et al. (2018), que inferiram que o aprendizado não fluiria com o mesmo êxito sem a participação do monitor, tornando-o elemento fundamental no processo de ensino-aprendizagem. Ressalta-se ainda que nas disciplinas abordadas são realizadas aulas de revisão, listas de exercícios, apostila com questões de concurso e provas anteriores, implementação da Aprendizagem Baseada em Jogos, em que aplicativos como o Kahoot! são utilizados para auxiliar no acompanhamento e evolução do aluno na disciplina, além de 
possibilitar a dinamicidade da aula (MOTA; BARROSO; OLIVEIRA, 2018). Na disciplina de Topografia, devido à parte prática, o monitor também auxilia na realização dessas aulas práticas em campo.

No tocante à discordância parcial ou total, a Afirmação (2) se destacou. Um percentual de, aproximadamente, $49 \%$ discordou totalmente ou parcialmente sobre a monitoria ser um processo de aprendizagem formal. Quando considerados os neutros, esse percentual sobe para $71 \%$. Lechado et al. (2019) atenuam que a proximidade entre alunos e monitores gera um ambiente no qual eles se sentem mais próximos do conteúdo, em que certa informalidade com que o conhecimento é transmitido, atrelada à diferenciada forma didática dos monitores, torna o programa de monitoria uma ferramenta importante de complementação no processo de aprendizagem. Andrade et al. (2018) perceberam que a monitoria se torna um processo dinâmico perante o contato entre monitores, alunos e professores.

Contudo, ainda há uma parcela de 29,3\% dos entrevistados que concorda parcialmente e totalmente sobre a monitoria ser um processo formal. Frison e Moraes (2010) observam que:

mesmo quando podem contar com a ajuda adequada de alguém, neste caso dos monitores, os alunos inibem-se diante dos obstáculos, apresentando dificuldades para superá-los. (FRISON; MORAES, 2010, p. 153)

Isso pode remeter ao processo formal de aprendizagem, no qual os alunos são apenas receptores de conteúdo. Essa observação ressalta o observado na Afirmação (4), em que o número de neutralidade e concordância parcial ao sentimento de igualdade entre monitores e alunos é superior aos demais níveis da Escala Likert juntos. O aluno, por inibição, acaba não sentindo essa igualdade, mesmo que o ensino na monitoria decorra entre pares entre alunos e monitores que, na maioria das vezes, detém o mesmo tipo de raciocínio ou pensamento. Para Silveira e Sales (2016), o monitor utiliza a sua vivência na disciplina para identificar com mais veemência os pontos fracos dos alunos e este pode ser visto apenas como um aluno que está mais avançado no mesmo curso.

A Afirmação (6) é a segunda com o maior registro de concordância total, na qual se admite que o monitor pode ser visto como elemento de interlocução e mediação entre a turma e o professor. As concordâncias totais e parciais, juntas, representam 95,1\% das percepções totais, o que é corroborado por Nunes (2007), que afirma que a opinião do monitor é um fator importante para a construção do processo de ensinoaprendizagem, visto que ele é como um elo entre o professor e os alunos. A partir desse resultado, também pode ser identificada uma abordagem sociocultural, proposta por Mizukami (1986), que valoriza a interação entre os sujeitos e entre o sujeito e o objeto de estudo. Isso remete à interação professormonitor e monitor-turma, possibilitando a intercalação entre o professor-turma, sendo essas experiências essenciais quando trazidas da turma para o docente. Além disso, Silveira e Sales (2016) observam que o monitor continua sendo aluno, facilitando a identificação de possíveis dificuldades apresentadas, contribuindo para tornar mais compreensível a comunicação entre professor e aluno.

A abordagem proposta por Mizukami (1986) pode ser associada ao resultado da Afirmação (1), na qual 95,6\% dos registros concordam totalmente ou parcialmente que a monitoria propicia troca de saberes e experiência. As respostas podem ser sustentadas pela observação de Moutinho (2015):

a monitoria se estabelece como um processo que oferece melhorias no ensino por meio do convívio, da troca de experiências, das dificuldades observadas e encontradas [...] (MOUTINHO, 2015, p. 18)

Para Vigotski (1984), o contato com um grupo cultural auxilia no desenvolvimento do ser humano, ao se basear no aprendizado e na troca direta ou indireta de experiências, demonstrando um benefício dessa troca de saberes e experiência.

No tocante à Afirmação (3), Queiroz e Barzaghi (2007) afirmam que a participação 
dos monitores visa a facilitar o processo de ensino-aprendizagem, permitindo um maior envolvimento dos alunos, propiciando uma relação de proximidade com os alunos, que passam a se sentir mais próximos dos monitores. Santos e Lins (2007) afirmam que o monitor desempenha uma função educativa catalisadora na difusão do conhecimento, tornando-se um participante ativo no processo ensino-aprendizagem. Dessa forma justifica-se que todos os alunos tenham concordado parcialmente ou totalmente com o fato de a monitoria facilitar a disseminação do conhecimento.

As afirmações (5) e (7) se relacionam sequencialmente. A primeira afirma que a monitoria reforçou o conteúdo ministrado nas aulas, havendo uma concordância total de $68,3 \%$ e uma concordância parcial e total de 97,6\%. A segunda afirmação, após esse reforço de conteúdo, admite que o discente se sentiu mais preparado para a realização das provas, para a qual houve uma neutralidade de $7,3 \%$ dos registros, sendo os demais de concordâncias parciais e totais. Ambos os resultados obtidos entram em acordo com a observação de Frison e Moraes (2010), que afirmam que a monitoria é uma importante tática de trabalho no mundo acadêmico, devido ao fortalecimento do ensino e da aprendizagem que ela causa. Andrade et al. (2018) ressaltam que a monitoria é um processo promotor do aprendizado, considerando que o aluno, ao se apoiar no monitor, encontra um ambiente propício para esclarecer suas dúvidas, fortalecer suas habilidades e potencializar seus conhecimentos com um menor grau de receio.

\section{CONCLUSÕES}

Este estudo descreveu a percepção de discentes no tocante às contribuições da monitoria em disciplinas ofertadas pelo Departamento de Engenharia de Transportes da Universidade Federal do Ceará, como elemento de fortalecimento do processo de ensinoaprendizagem. Conforme os dados obtidos dos alunos envolvidos nesta pesquisa, a monitoria é uma importante aliada à melhoria da educação superior e à consolidação dos processos de ensino-aprendizagem. A monitoria foi descrita como uma estratégia de apoio ao ensino, que colabora no processo de aprimoramento do conhecimento dos discentes, sendo propulsora e fortalecedora desse processo. Existe a percepção de que a monitoria contribui para renovação do conhecimento, considerando-o como dinâmico, que se transforma continuamente.

Dessa forma, foi possível perceber que a monitoria é um agente que - por meio das aulas de monitoria realizadas, dos jogos desenvolvidos, do apoio com materiais didáticos, como listas de exercícios, cronograma de estudos, apostila de questões de avaliações anteriores - fortalece o conteúdo repassado em sala de aula. Esse fortalecimento torna possível que o aluno se sinta mais confiante pelo aprendizado conquistado, bem como para realizar as avaliações da disciplina, apesar, e principalmente, dela não ser vista como um elemento formal de ensino.

Devido ao fato de não ser totalmente considerada um método formal de ensino, no qual o aluno atua como agente passivo no processo de ensino-aprendizagem, há um sentimento de igualdade entre os alunos e o monitor. Essa percepção de paridade não vem somente da visão do monitor como uma referência, mas por considerarem que ele os auxilia na ascensão do aprendizado, com uma certa cumplicidade. $\mathrm{O}$ monitor, por se encontrar na condição de discente, compreende os anseios e angústias de seus colegas, passando a ser interlocutor da turma com o professor na reivindicação de causas de interesse mútuo, tendo como objetivo final o conhecimento.

A partir dos resultados deste estudo, que relevam que a monitoria contribui diretamente para o êxito ao final da disciplina, ressalta-se a necessidade de maior incremento institucional e visibilidade ao programa de monitoria por parte da comunidade acadêmica, considerando sua relevância para os discentes. Além disso, cabe ser destacada a carência de estudos da relação entre a monitoria e o processo de ensino-aprendizagem dos cursos de Engenharia, incluindo, também, a percepção de monitores e professores e os ganhos 
acadêmicos e profissionais que o programa propicia.

\section{AGRADECIMENTOS}

Agradecimentos especiais ao Conselho Nacional de Desenvolvimento Científico e Tecnológico - CNPq, pela bolsa de mestrado do primeiro autor; e aos alunos respondentes.

\section{REFERÊNCIAS}

AGUIAR, C. R. L. et al. Estratégias de ensino desenvolvidas através de ambientes não formais em um curso de engenharia. Revista de Ensino de Engenharia, v. 35, n. 1, p. 5764, 30 jun. 2016.

AMORIM, T. B.; PAIXÃO, M. de F. M.; SILVA, A. G. C. da. A importância da monitoria para o aprendizado de Química. Revista de Ensino de Engenharia, v. 36, n. 2, p. 27-34, 2017.

ANDRADE, E. G. R. et al. Contribution of academic tutoring for the teaching-learning process in Nursing undergraduate studies. Revista Brasileira de Enfermagem, v. 71, n. 4, p. 1596-1603, 2018.

ARAÚJO, M.; PIRES, P.; DOS SANTOS, E. Monitoria como atividade de ensinoaprendizagem sob a ótica de acadêmicos de enfermagem. Revista Enfermagem Atual In Derme, v. 89, n. 27, 25 set. 2019.

ARAÚJO, R.; MOREIRA, L. F. N. Monitoria da disciplina de Cálculo. Anais... Congresso Brasileiro de Educação em Engenharia. ed. 33, 2005, Campina Grande. Campina Grande: ABENGE, 2005.

BACKER, P. de. Gestão ambiental: A administração verde. Rio de Janeiro: Qualitymark, 1995.

BRASIL. Lei no 9.394, de 20 de dezembro de 1996. Diretrizes e Bases da Educação Nacional. Brasília, Disponível em: http://www.planalto.gov.br/ccivil_03/leis/1939 4.htm. Acesso em: 02 de mai. 2020.

FERRAZ, L. V. et al. Importância da monitoria na formação acadêmica do monitor. Anais...
JEPEX 2009 - IX Jornada de ensino, pesquisa e extensão da UFRPE, Recife, 2009. Disponível em: http://www.eventosufrpe.com.br/jepex2009/c d/resumos/R0334-2.pdf. Acesso em: 02 de mai. 2020.

FRISON, L. M. B.; MORAES, M. A. C. de. As práticas de monitoria como possibilitadoras dos processos de autorregulação das aprendizagens discentes. Poíesis Pedagógica, v. 8, n. 2, p. 144-158, 2010.

JESUS, D. M. O. et al. Programas de monitorias: um estudo de caso em uma IFES. Revista Pensamento Contemporâneo em Administração. v.6, n.4, p. 61-86, 2012. Disponível em: https://www.redalyc.org/articulo.oa? $\mathrm{id}=44174$ 2847004. Acesso em: 17 de mar. 2020.

LECHADO, G. de O. et al. Evolução do desempenho acadêmico nas disciplinas de estruturas através da monitoria e projeto de ensino. Anais... Congresso Brasileiro de Educação dm Engenharia. ed. 47, Fortaleza: ABENGE, 2019.

LINS, Daniel. Ser monitor. 2007. Disponível em: http://www.mauriciodenassau.edu.br/artigo/ex ibir/cid/1/fid/1/aid/215. Acesso em: 17 de mar. 2020.

MATTAR, F. N. Pesquisa de marketing. Edição Compacta. 3.ed. São Paulo: Atlas, 2001.

MELO, F. G. Tecnologias educacionais e formação discente: o caso da monitoria de cálculo numérico nos cursos de engenharia do Campus do Sertão/UFAL. Anais... Congresso Brasileiro de Educação dm Engenharia, ed. 41, Gramado: ABENGE, 2013.

MENESTRINA, T. C.; BAZZO, W. A. Ciência, tecnologia e sociedade e formação do engenheiro: análise da legislação vigente. Revista Brasileira de Ensino de Ciência e Tecnologia, v. 1, n. 2, p. 1-18, 1 jun. 2008.

MESQUITA, S. K. da C.; MENESES, R. M. V.; RAMOS, D. K. R. Metodologias ativas de ensino/aprendizagem: dificuldades de docentes de um curso de enfermagem. Trabalho, Educação e Saúde, v. 14, n. 2, p.473-486, 1 abr. 2016. 
MIZUKAMI, M. da G. N. Ensino: as abordagens do processo. São Paulo: EPU, 1986.

MOTA, B. C.; BARROSO, S. H. de A.; OLIVEIRA, F. H. L. de. A ferramenta Kahoot aplicada à disciplina de Projeto e Construção da Superestrutura Viária. Anais... Congresso Brasileiro de Educação dm Engenharia, ed. 46, Salvador: ABENGE, 2018.

MOUTINHO, P. M. N. Monitoria: sua contribuição para o ensino-aprendizagem na Graduação em Enfermagem. 2015. 60 f. Dissertação (Mestrado) - Mestrado em Ciências, Escola de Enfermagem de Ribeirão Preto, Universidade de São Paulo, Ribeirão Preto, 2015.

NUNES, J. B. C. Monitoria acadêmica: espaço de formação. In: SANTOS, M. M. dos; LINS, N. de M. (org.). A monitoria como espaço de iniciação à docência: possibilidades e trajetórias. Natal: EDUFRN, 2007.

PINHEIRO, T. S. et al. A monitoria como via de mão dupla no processo de ensinoaprendizagem: estudo de caso em um projeto de ensino, pesquisa e extensão. Anais... Congresso Brasileiro de Educação dm Engenharia, ed. 47, Fortaleza: ABENGE, 2019.

\section{PROGRAD. Bolsas do Programa de Iniciação à} Docência. 2020. Disponível em: https://prograd.ufc.br/bolsas/bolsas-do-pidprograma-de-iniciacao-a-docencia/. Acesso em: 30 de abr. 2020.

QUEIROZ, A. F. S. de; BARZAGHI, R. A. A monitoria na disciplina de biofísica: um relato de experiência. In: SANTOS, M. M. dos; LINS, N. de M. (org.). A monitoria como espaço de iniciação à docência: possibilidades e trajetórias. Natal: EDUFRN, 2007.

SANTOS, D. F.; BOSCAINO, E. G.; PAVÃO, A. C. Avaliação da contribuição da monitoria para o desempenho do aluno de engenharia: um estudo de caso na Escola de Engenharia Mauá. Anais... Congresso Brasileiro de Educação dm Engenharia, ed. 34, Passo Fundo: ABENGE, 2006.
SANTOS, M. M.; LINS, N. de M. A monitoria na universidade federal do Rio Grande do Norte: um resgate histórico. In: SANTOS, M. M. dos; LINS, N. de M. (org.). A monitoria como espaço de iniciação à docência: possibilidades e trajetórias. Natal: EDUFRN, 2007.

UFC. Resolução $n^{\circ}$ 08, de 26 de abril de 2013. Regulamentação do Programa de Iniciação à Docência da UFC. Fortaleza, Disponível em: $\quad$ https://prograd.ufc.br/wpcontent/uploads/2014/05/pid-anexo-vresolucao-regulamentadora-08-2013.pdf. Acesso em: 15 de mar. 2020.

SILVEIRA, E.; SALES, F. de. A importância do Programa de Monitoria no ensino de Biblioteconomia da Universidade do Estado de Santa Catarina (UDESC). Revista de Ciência da Informação e Documentação, v. 7, n. 1, p. 131-149, 5 abr. 2016.

SOUSA JÚNIOR, J. A. de; SILVA, A. L. da; MAGNO, A.; SANTOS, M. B. H. dos; BARBOSA, J. A. Importância do monitor no ensino de Química Orgânica na busca da formação do profissional das ciências agrárias. Anais... XI Encontro de Iniciação à Docência, João Pessoa, v. 6, n. 1, p. 1-5, 2009.

VIGOTSKI, L. S. A formação social da mente. São Paulo: Martins Fontes, 1984. 


\section{DADOS BIOGRÁFICOS DOS AUTORES}
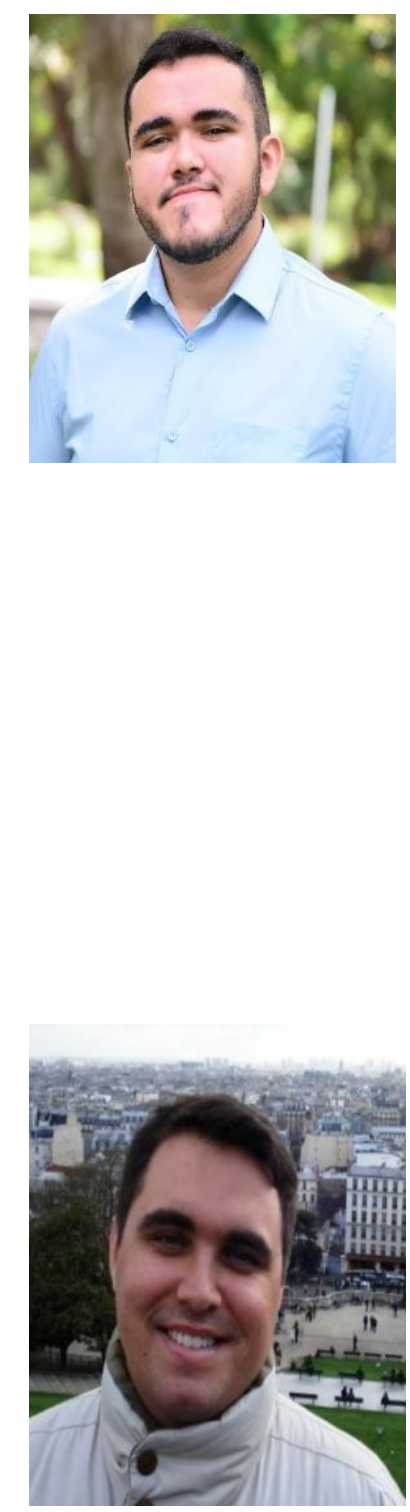

Bruno Cavalcante Mota - Engenheiro Civil formado pela Universidade Federal do Ceará (2020). Mestrando em Engenharia de Transportes na área de concentração de Infraestrutura pela Universidade Federal do Ceará no Programa de Pós-Graduação em Engenharia de Transportes (PETRAN). Bolsista CNPq. Tem experiência na área de pavimentação, onde acompanhou a construção de trecho experimental com cinzas de carvão mineral nas camadas de base e subbase do pavimento. Foi bolsista de pesquisa do Laboratório de Solos no CTAsfalto, vinculado ao projeto "Aplicação prática das cinzas de carvão mineral na pavimentação". Exerceu atividades como bolsista do Programa de Iniciação à Docência nas disciplinas de Projeto e Construção da Infraestrutura Viária e Projeto e Construção da Superestrutura Viária, ofertadas pelo Departamento de Engenharia de Transportes no referido curso durante todo o ano de 2018 e novamente na segunda disciplina citada durante o primeiro semestre de 2019. Em 2017 atuou como bolsista de extensão na Seara da Ciência (órgão de divulgação científica e tecnológica da UFC), ministrando aulas de Física para alunos do ensino médio da rede pública de ensino de Fortaleza. Já foi bolsista da Secretaria de Tecnologia da Informação e voluntário no Programa de Aprendizagem Cooperativa em Células Estudantis, com uma célula de estudos acerca da disciplina de Análise e Planejamento do Sistema de Transportes. Possui artigos publicados no Congresso Brasileiro de Educação em Engenharia, abordando metodologias ativas de ensino. Foi premiado com o $1^{\circ}$ lugar na $1^{\text {a }}$ Mostra Científica do Curso de Engenharia Civil da UFC.

Francisco Heber Lacerda de Oliveira - Doutor em Engenharia de Transportes (2016) pelo Programa de Pós-Graduação em Engenharia de Transportes da Universidade Federal do Ceará (PETRAN/UFC). Professor Adjunto do Departamento de Engenharia de Transportes da Universidade Federal do Ceará (DET/UFC). Atualmente, é Vice Coordenador do Programa de Pós-Graduação em Engenharia de Transportes da Universidade Federal do Ceará. Tem experiência em Transporte Aéreo e Aeroportos, Operação, Manutenção e Reabilitação de Infraestruturas Aeroportuárias, especialmente em pavimentos flexíveis e rígidos de pátios e de pistas de pouso e decolagem. Desenvolve metodologias ativas nas disciplinas que ministra no curso de Engenharia Civil. 